\title{
A Correlation Study of Nadal's and Federer's Technical Indicators in Different Tennis Arenas
}

\author{
Kun Tian, Meifang Zhou, Qian Zhao, Zuhua Xie \\ Jiangxi Normal University, Nanchang, China
}

Keywords: Federer; Nadal; correlation analysis; technical indicators.

\begin{abstract}
The objective of this paper is to explore Nadal and Federer's technical indicators and scores in the tennis match and the relevance of the venue, and provide theoretical guidance for tactical choices for tennis matches at different venues. The literature indexes of Federer and Nadal's 38 games were analyzed by using the literature method, video observation method and correlation analysis method. The tactical characteristics, technical indicators, scores and associations with the venues were explored. Results show that Federer uses more offensive tactics in technical indicators, and it is suitable for fast courses such as hard ground and grass. Nadal uses more defensive tactics in technical indicators and is suitable for slow courts such as clay courts. Therefore, in tennis matches, tactics should be chosen according to different playing fields. In slow games, defensive tactics should be selected more. In fast games, offensive tactics should be applied.
\end{abstract}

\section{Introduction}

Tennis is a kind of racket-based netting-type physical activity program. It has high requirements for athletes' physical strength, endurance and reactivity, and it has always been an international high-level sports competition project. It is highly valued by the sports departments of various countries. In recent years, tennis has developed rapidly in China. However, due to the late introduction, lack of relevant technology reserves, and low popularity, there have been few achievements in international tennis events. Federer and Nadal, as the representative athletes of the highest tennis skills, have their own characteristics of tennis skills and tactics in both fast and slow courses. They analyze their technical characteristics and tactical use in different venue tennis events and summarize their responses to different venues. The experience of competition players has important reference significance for the training of youngsters and professional tennis players in China.

\section{Research objects and methods}

\subsection{Research object}

In this study, Federer and Nadal's 38 matches in the 2004-2017 international professional tennis competition were studied. The two sides analyzed ACE, double errors, one-shot success rate, one-shot scoring rate, and two-time scoring rate at different venues, save the break point success rate, serve the number of games, then take the success rate, the number of receiving the ball, grasp the success rate of the break point, then win the score, the success of the serve, the service score and the total score of 14 Tennis technical indicators.

\subsection{Research methods}

Document Data Method. Through the Chinese-Korean database, Wei Pu Chinese database and web of science database and other Chinese and English databases, comprehensive search of tennis technical and tactical periodicals and monographs was conducted. The technical and tactical characteristics of various types of tennis matches were summarized and summarized, laying the foundation for this study. basis. Through the ATP official website, the official website of the four 
official tennis tournaments, and tennis clubs and other sites to collect data related to this study of tennis competitions, to provide reliable data analysis for this study.

Video observation. Federer and Nadal men's singles match video was watched and related technical indicators were collected to provide initial data for later data analysis. By observing the video of the match, we will focus on the statistics of the 14 technical and tactical indicators and the technical and tactical features of Federer and Nadal in the game.

Mathematical Statistics. Using descriptive statistical data analysis methods, the data collected from video observations was analyzed layer by layer to explore the technical and tactical characteristics of Federer's and Nadal's game serve-ups, serve-to-go, and total scores. The technical and tactical data collected using Excel software were collected. Correlative analysis is performed to obtain the relevance of each game.

Comparative Analysis. Federer passed the SLR shot, the choice of batting line made different sub-targets, and achieved different tactical effects. Nadal passed double counter-attacks and the batting route was the opposite of Federer's. The tactical effects of the two reached continuous confrontation.

Logical Analysis. The grey correlation analysis focuses on analyzing 14 indicators in 38 games between Federer and Nadal, and obtains the highest correlation index in each game through the correlation algorithm, and analyzes the relationship between this indicator and other indicators. The relevance of the indicators reflects the tactical type.

\section{Research results and analysis}

\subsection{Correlation analysis between technical indicators and scores}

The competitive level of tennis players can be evaluated comprehensively by using long-term game data to calculate the relevance of 14 related technical indicators and total scores. In this study, by counting the average number of technical indicators of Federer and Nadal, the maximum and minimum values of all indicators were found. Finally, the correlation degree values were determined using the grey correlation analysis method, and the tennis technical characteristics of the two were performed. Overview.

Gray Correlation Analysis of Federer Tennis Technical Index and Total Score. By analyzing Federer's 14 technical indicators in 38 games of tennis, it was found that there are 10 indicators with the highest degree of correlation and individual indicators repeat in different venues. The specific results are: ACE 5 times ( 4 wins and 1 loss), double 7 errors (2 wins and 5 losses), 1 success rate 3 times ( 3 losses), 2 rate points 2 times ( 1 win 1 loss), 6 points to save the break point success rate ( 3 wins and 3 losses), then one Winning score 3 times ( 1 win and 2 losses), number of receiving serve 4 times (4 losses), success rate of 6 points (3 wins and 3 losses) at break point, and 1 win (1 loss) after winning 2 points The score for the second and second rounds ( 1 win and 1 loss). Through the analysis of Federer's game tactics, he often uses offensive tactics and uses most of the tactics to break the Nadal's serve while using the ACE to score directly, improve the success rate of the serve, score before the net, and save the success rate of the break point. Score, see Table 1 for details.

Table 1 Federer technical indicators relevance

\begin{tabular}{ccccccccccc}
\hline & ACE & Double & $\begin{array}{c}1^{\text {st }} \\
\text { serve } \\
\text { (in) }\end{array}$ & $\begin{array}{c}2^{\text {nd }} \text { serve } \\
\text { points } \\
\text { won }\end{array}$ & $\begin{array}{c}\text { Break } \\
\text { points }\end{array}$ & $\begin{array}{c}1^{\text {st }} \text { serve } \\
\text { return } \\
\text { points } \\
\text { won }\end{array}$ & $\begin{array}{c}\text { Return } \\
\text { games } \\
\text { played }\end{array}$ & $\begin{array}{c}\text { Break } \\
\text { points } \\
\text { converted }\end{array}$ & $\begin{array}{c}2^{\text {nd }} \text { serve } \\
\text { return } \\
\text { points } \\
\text { won }\end{array}$ & $\begin{array}{c}\text { Total } \\
\text { return } \\
\text { points } \\
\text { won }\end{array}$ \\
\hline Win & 4 & 2 & 0 & 1 & 3 & 1 & 0 & 3 & 0 & 0 \\
Negative & 1 & 5 & 3 & 1 & 3 & 2 & 4 & 3 & 1 \\
\hline
\end{tabular}

Grey Relational Analysis of Nadal's Tennis Technical Index and Total Score. Nadal's correlations between technical indicators and total scores in 38 games are: ACE9 (6 wins and 3 losses), double errors ( 5 wins and 3 losses), two rounds of scoring (2 negatives), and grasping. Breakpoint success rate 7 times ( 5 wins and 2 losses), followed by two winning points once ( 1 win), followed by a 
winning score 3 times ( 2 wins and 1 loss), a success rate of 2 times ( 1 win 1 ), a score rate of 1 (1 loss), and a save break point of 4 times (3 wins and 1 loss). By analyzing Nadal's scoring factors in the above games, he found that the number of strokes is the key to his success score. The more he hits the ball, the greater the probability of successful scoring, and his advantage in the two technical indicators of ACE and double errors. Increase the probability of winning. See Table 2 for details.

Table 2 Correlation of Nadal technical indicators

\begin{tabular}{ccccccccccc}
\hline & ACE & Double & $\begin{array}{c}1^{\text {st }} \text { serve } \\
\text { (in) }\end{array}$ & $\begin{array}{c}2^{\text {nd }} \text { serve } \\
\text { points } \\
\text { won }\end{array}$ & $\begin{array}{c}\text { Break } \\
\text { points }\end{array}$ & $\begin{array}{c}1^{\text {st }} \text { serve } \\
\text { return } \\
\text { points } \\
\text { won }\end{array}$ & $\begin{array}{c}\text { Return } \\
\text { games } \\
\text { played }\end{array}$ & $\begin{array}{c}\text { Break } \\
\text { points } \\
\text { converted }\end{array}$ & $\begin{array}{c}2^{\text {nd }} \\
\text { serve } \\
\text { return } \\
\text { points } \\
\text { won }\end{array}$ & $\begin{array}{c}\text { Total } \\
\text { return } \\
\text { points } \\
\text { won }\end{array}$ \\
\hline Win & 6 & 5 & 1 & 0 & 3 & 2 & 0 & 5 & 0 & 0 \\
Negative & 3 & 3 & 1 & 2 & 1 & 1 & 2 & 2 & 1 & 0 \\
\hline
\end{tabular}

\subsection{Correlation analysis between technical indicators and competition venues}

Analysis of Federer's association in different competition venues. Federer's associated technical indicators won in hard courts are to save the break point success rate, ACE, double error, success rate of break points, second-round scoring rate, success-per-game score, success rate, and serve The number of winning matches, the score of winning two games, and the winning percentage of the receiving game; the associated technical indicators winning in the clay court are only able to determine the success rate of breaking; the associated technical indicator that wins in the grass playing field is only ACE. By analyzing the relevance of Federer's different venues and technical indicators, it is found that in the tennis game, its offensive tactics are more effective in hard and grasslands, and can not achieve better scores in the clay court. See Table 3 for details.

Table 3 Federer Red Clay, Hard Land, Grassland Technical Index Correlation

\begin{tabular}{|c|c|c|c|c|c|c|c|c|c|c|c|}
\hline & & ACE & Double & $\begin{array}{c}1^{\text {st }} \\
\text { serve } \\
\text { (in) }\end{array}$ & $\begin{array}{c}2^{\text {nd }} \\
\text { serve } \\
\text { points } \\
\text { won }\end{array}$ & $\begin{array}{l}\text { Break } \\
\text { points }\end{array}$ & $\begin{array}{c}1^{\text {st }} \\
\text { serve } \\
\text { return } \\
\text { points } \\
\text { won }\end{array}$ & $\begin{array}{l}\text { Return } \\
\text { games } \\
\text { played }\end{array}$ & $\begin{array}{c}\text { Break } \\
\text { points } \\
\text { converted }\end{array}$ & $\begin{array}{c}2^{\text {nd }} \\
\text { serve } \\
\text { return } \\
\text { points } \\
\text { won }\end{array}$ & $\begin{array}{l}\text { Total } \\
\text { return } \\
\text { points } \\
\text { won }\end{array}$ \\
\hline \multirow{2}{*}{$\begin{array}{c}\text { Hard } \\
\text { Ground }\end{array}$} & Win & 2 & 2 & 0 & 1 & 3 & 1 & 0 & 2 & 0 & 0 \\
\hline & Negative & 0 & 2 & 2 & 1 & 3 & 0 & 0 & 1 & 0 & 0 \\
\hline \multirow[t]{2}{*}{ Red Earth } & Win & 0 & 0 & 0 & 0 & 0 & 0 & 0 & 1 & 0 & 0 \\
\hline & Negative & 0 & 3 & 0 & 0 & 0 & 2 & 4 & 2 & 1 & 1 \\
\hline \multirow[t]{2}{*}{ Grassland } & Win & 2 & 0 & 0 & 0 & 0 & 0 & 0 & 0 & 0 & 0 \\
\hline & Negative & 1 & 0 & 0 & 0 & 0 & 0 & 0 & 0 & 0 & 0 \\
\hline
\end{tabular}

Table 4 Correlation of technical indicators in Nadar red clay, hard land, and grassland

\begin{tabular}{|c|c|c|c|c|c|c|c|c|c|c|c|}
\hline & & ACE & Double & $\begin{array}{c}1^{\text {st }} \\
\text { serve } \\
\text { (in) }\end{array}$ & $\begin{array}{c}2^{\text {nd }} \\
\text { serve } \\
\text { points } \\
\text { won }\end{array}$ & $\begin{array}{c}\text { Break } \\
\text { points }\end{array}$ & $\begin{array}{c}1^{\text {st }} \\
\text { serve } \\
\text { return } \\
\text { points } \\
\text { won }\end{array}$ & $\begin{array}{l}\text { Return } \\
\text { games } \\
\text { played }\end{array}$ & $\begin{array}{c}\text { Break } \\
\text { points } \\
\text { converted }\end{array}$ & $\begin{array}{c}2^{\text {nd }} \\
\text { serve } \\
\text { return } \\
\text { points } \\
\text { won }\end{array}$ & $\begin{array}{c}\text { Total } \\
\text { return } \\
\text { points } \\
\text { won }\end{array}$ \\
\hline \multirow{2}{*}{$\begin{array}{c}\text { Hard } \\
\text { Ground }\end{array}$} & Win & 3 & 2 & 0 & 0 & 0 & 0 & 0 & 3 & 1 & 0 \\
\hline & Negative & 2 & 3 & 1 & 0 & 0 & 1 & 0 & 2 & 0 & 0 \\
\hline \multirow[t]{2}{*}{ Red Earth } & Win & 2 & 3 & 1 & 1 & 3 & 2 & 0 & 2 & 0 & 0 \\
\hline & Negative & 0 & 0 & 0 & 0 & 1 & 0 & 0 & 0 & 0 & 0 \\
\hline \multirow[t]{2}{*}{ Grassland } & Win & 1 & 0 & 0 & 0 & 0 & 0 & 0 & 0 & 0 & 0 \\
\hline & Negative & 1 & 0 & 0 & 0 & 0 & 0 & 0 & 0 & 0 & 0 \\
\hline
\end{tabular}

Association Analysis of Nadal in Different Playing Fields. Nadal's associated technical indicators won in the hard court venues are ACE, double errors, success rate at the break point, and winning scores at the second break; the winning technical indicators for the clay court are ACE, double errors, and success rate. Second, the score rate, save the success rate of the break point, followed by a winning score, and the success rate of the break point; the relevant technical index of the grass court is 
only ACE. By analyzing the association between Nadal's tennis venues and technical indicators, it is found that Nadal uses more tactical types in the clay court and uses more technical indicators. Although the technical indicators of double faults are high, the success rate of the breaks is improved by improving the success rate. Form tactical complementarity and increase the probability of scoring. See Table 4 for details.

\section{Conclusion}

\subsection{Characteristics of Technical Types of Federer and Nadal}

This article finds Federer's technical indicators for increasing Federer's scoring rate in the match with Nadal by using grey correlation analysis: ACE, double error, success rate, second rate, save break point success rate, and success. Rate and grasp the success rate of break points, of which 5 are service indicators. Therefore, Federer tends to use offensive tactics in tennis, increasing his chances of scoring and winning games by increasing the use of serving techniques. The technical indicators to improve Nadal's scoring rate are mainly to save the success rate of the break point, score points to win the match, and take over the ball-type indicators such as break points. In the game, they are more inclined to use defensive tactics.

\subsection{Federer and Nadal's tactical effects in different venues}

Nadal wins 24 games in 38 games with Federer. Among them, Nadal has won 9 games in the hard court, 14 in the clay court, and 1 in the grass court. Federer won 14 games, including 11 in the hard court. The clay court won 1 field and the grass court won 2 games. Combining the tactical characteristics of both and the venue, Nadal is able to play defensive technology better on the clay court. This is in contrast to the slow speed of tennis spinning on the clay court relative to hard and grassland. Federer's offensive tactics are The slow course cannot be formed. And in fast courses such as hard ground and grass, offensive

\subsection{Federer and Nadal's technical and tactical strategies in different venues}

Federer's indicators on different venues are biased towards serving targets in 38 matches played by Gray Relevance Analysis. In particular, in the serve game, ACE indicators are used to increase the number of scores and shorten the time of continuous confrontation with Nadal. In order to increase the time for rest, he will continue to fight against Nadal's serve and continue to undermine Nadal's serve. On the contrary, Nadal's indicators on different venues tend to receive ball indicators, especially on the success rate of break points. This indicator has won more competitions. Therefore, in response to offensive tennis players, the proactive defensive tactics should be used to increase the probability of scoring. In response, defensive players must pay attention to the success rate of break points to increase the chance of scoring.

\section{References}

[1] Zhu Xianbin. Comparative Analysis of the Technical and Tactical Characteristics of Djokovic's Serving Stage in Tennis Match[D]. Shaanxi Normal University, 2016.

[2] Du Suqing. Research on the "key indicators" of tactics and tactics in tennis [D]. Beijing Sport University, 2015.

[3] Sun Yang. Research on the characteristics of Djokovic's serve tactics in the hard tennis game[D]. Xi'an Institute of Physical Education, 2014.

[4] Li Tengfei. Comparative study on the skills and tactics of the top 8 men's singles top 8 players at different venues[D]. Southwest University, 2014.

[5] Wang Yu, Guo Liya, Wang Juan. Correlation Analysis of Federer Serve and the Third-Punch Ball Return Line[J]. Journal of Jilin Institute of Physical Education, 2011, 27(01):42-44. 
[6] B Hongbo, Qian Zhiming, Zhang Haibin. Technical and tactical characteristics of the top 8 men's singles athletes in the 2010 Open Tennis Championships in Australia, France and Wenzhou[J]. China Sport Science and Technology, 2011, 47(01): 97-102.

[7] Liu Ye. Analysis of the Use of Tennis Tactics Online [J]. Sports World (Academic Edition), 2010, (11): 73-74.

[8] Huang Zhe. Research on the hitting routes in the hard court game of the world's best men's tennis players [D]. Beijing Sport University, 2010. 